\title{
GLL
}

Geomatics, Landmanagement and Landscape No. $1 \bullet 2021,7-22$

\section{LANDSCAPE INFORMATION MODELLING: AN IMPORTANT ASPECT OF BIM MODELLING, EXAMPLES OF CUBATURE, INFRASTRUCTURE, AND PLANNING PROJECTS}

\author{
Andrzej Szymon Borkowski, Michał Wyszomirski
}

\begin{abstract}
Summary
Land Information Modelling (LIM), increasingly popular among landscape architects and urban planners, is based on the use of urban space data that can be obtained from GIS systems. New models of buildings are simultaneously developed in BIM technology. This provokes an increasing need for integration of data from both areas for the use of shared BIM and GIS data in landscape design. The increasing popularity of the BIM technology not only forces designers to develop BIM models of buildings but also other land management objects, including infrastructure objects. Whereas it is possible to develop a model of an infrastructure object in specific BIM tools, the IFC data model for standardised exchange of BIM data does not offer the possibility to record data on objects other than buildings and their furnishings, and elements of land management are treated in a very general way. Transferring such a model by means of the IFC model requires the application of substitute classes of objects that are not relevant to the actual image of the model. Considering the above, the buildingSMART consortium conducts works on the expansion of the IFC model to permit modelling data on infrastructure objects. Provided the availability of valid spatial data from GIS systems and data concerning infrastructure objects already at the stage of design, systemic BIM and LIM can become a powerful landscape design tool based on current data and data concerning designed objects.
\end{abstract}

\section{Keywords}

landscape information modelling • building information modelling • IFC model

\section{Introduction}

As one of the latest trends in construction, Building Information Modelling (BIM), is rapidly becoming the key approach to digital integration of information required for object design, construction, and management. Studies to date have documented both advantages and disadvantages of the application of BIM tools and processes in building design and construction [Azhar et al. 2012; Isaac et al. 2017]. In current BIM projects and integrated design-construction practices, however, Land Information 
Modelling (LIM) is underestimated. The advantages offered by BIM to the industry at various scales have not been explored. Although some studies have evidenced the need for LIM platforms in the Architecture Engineering Construction (AEC)/Facility Management (FM) industry [Zajíčková and Achten 2013], there are still not enough theoretical or empirical studies regarding the development of complex patterns of defining the required objects, information, and attributes for LIM [Abdirad and Ken-Yu 2015]. Landscape architects and urban planners should be oriented at BIM [Ahmad and Aliyu 2012]. The BIM process also requires cooperation in the scope of the LIM design.

Design practice shows that the development of a 3D model (BIM3D) with potential further levels of advancement of the BIM model (BIM4D, 5D, etc.) can occur two-fold [Kasznia et al. 2018]. In the 'top-down' approach, the designer/designer team immediately develops a BIM model of the designed space (architecture, structures, installations, land management, etc.). In the 'bottom-up' approach, the model is based on the existing state of space management, after modelling of the existing elements (Fig. 1).

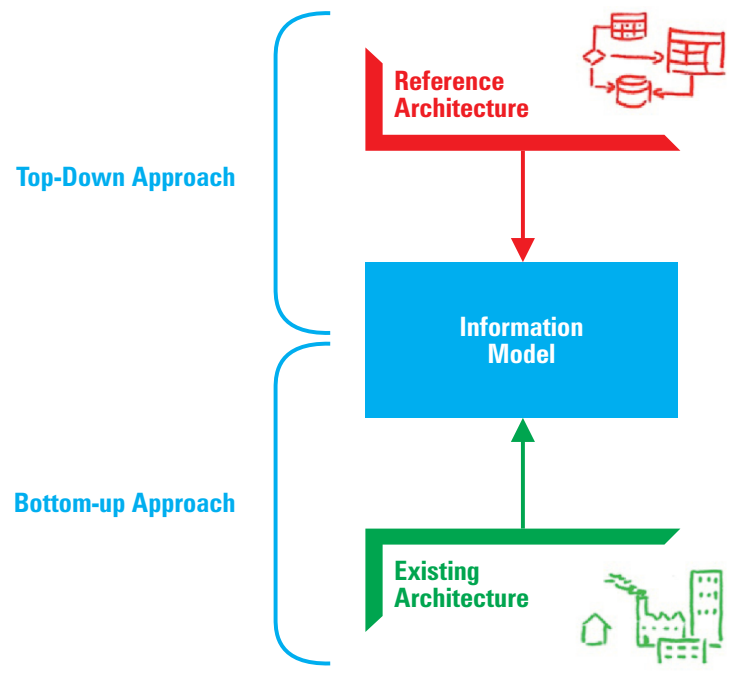

Source: Authors' own study

Fig. 1. Approaches to building a BIM/LIM model

\section{Subject and methodology of the research}

Building a coherent LIM solution requires standardization of methods of obtaining data on both models of buildings and other spatial development objects, as well as other elements of space. 
A very important element of the BIM technology is the possibility of sharing the model among all users in the process of design, construction, and operation of a building or structure. Achieving this goal is ensured by the application of the standardised IFC (Industry Foundation Classes) data model aimed at describing architectural, building, and construction industry data. IFC is generally normalised digital description of a built-up environment, including buildings and civil infrastructure. It is an open international standard ISO 16739-1:2018 aimed to be independent from software providers [BuildingSMART 2020]. BIM models developed so far have a limited number of IFC classes in the scope of landscape architecture and land management. It is exemplified by spaces of gardens, patios, playgrounds, or elements of small architecture that have no dedicated classes, but also solely based on classes designated for cubature objects (Fig. 2).

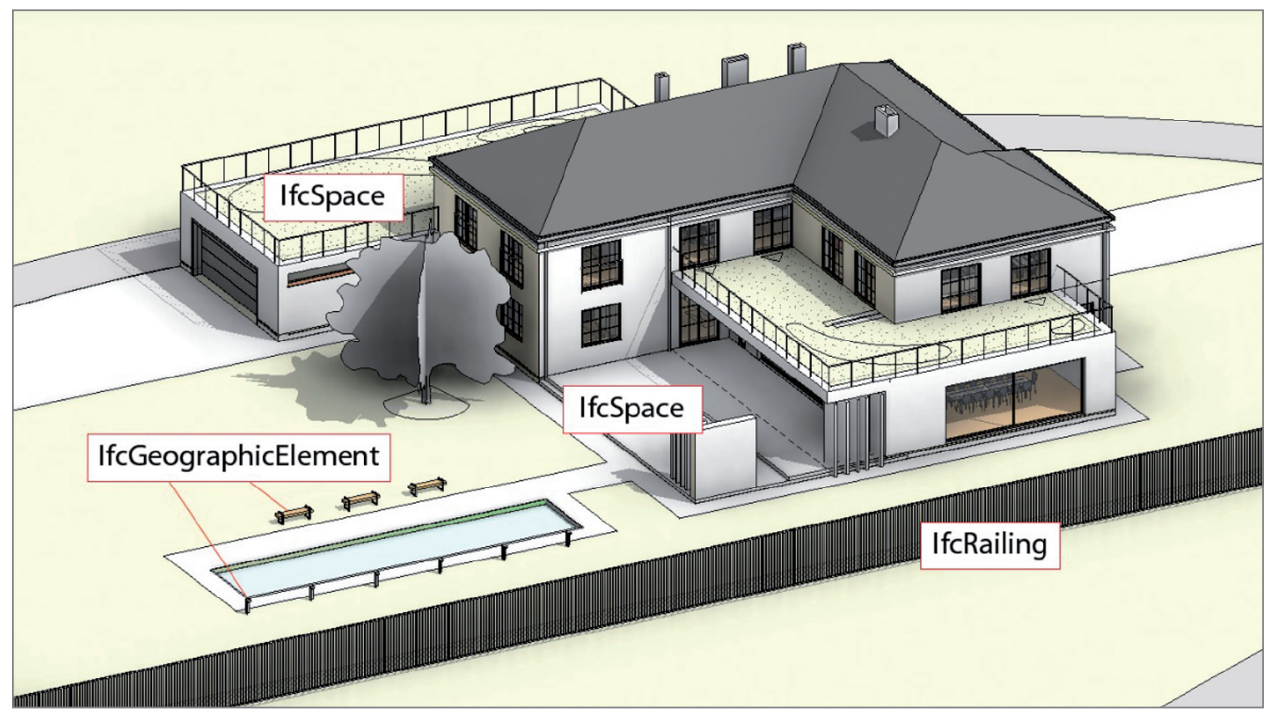

Source: Authors' own study based on a sample architectural model

Fig. 2. Classes of landscape objects in an IFC model

In the case of linear designs, saving an infrastructural BIM design in an IFC model with no definitions of classes of infrastructural objects will involve the necessity of compromise and use of classes available in the IFC model for saving objects in the model [Wyszomirski and Borkowski 2019]. Proposals of broadening the concept and standards of BIM for infrastructure are currently under preparation. The buildingSMART consortium is working on expanding IFC in the scope of representation of infrastructure. The current version of the IFC model primarily focuses on the domain of buildings, and covers a broad range of classes permitting exchange of detailed models of buildings, but is not suitable for modelling infrastructural objects (Fig. 3). 


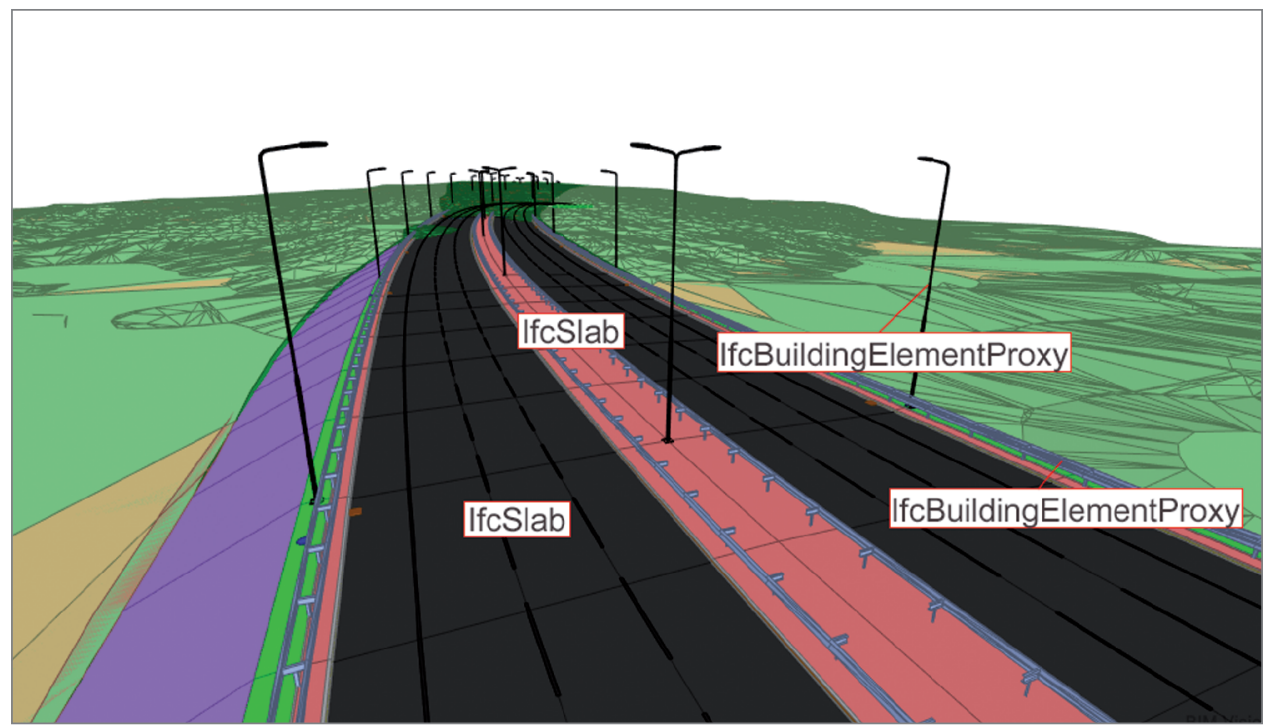

Source: Authors' own study based on the model from www.bimblog.pl

Fig. 3. Classes of objects of land management in an infrastructural model

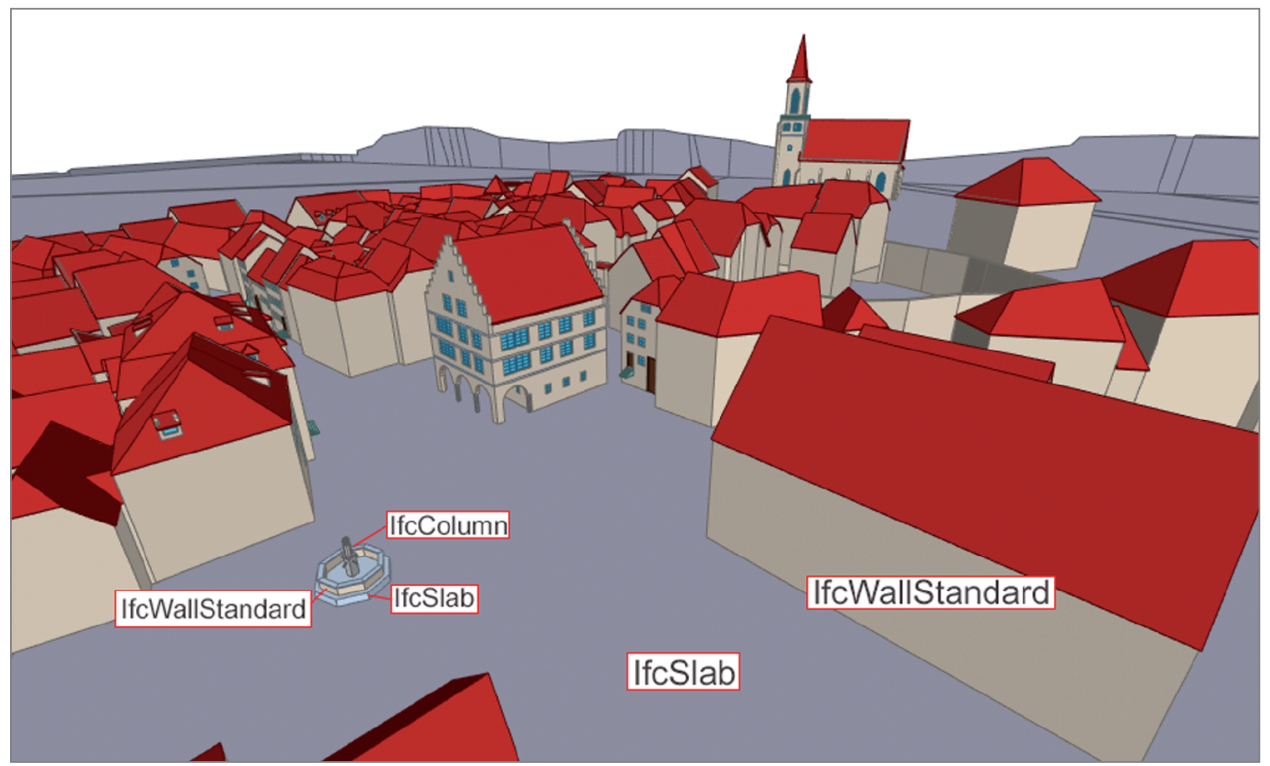

Source: Authors' own study based on the model from www.autodesk.com/autodesk-university/

Fig. 4. Classes of objects of land management in a planning project 
The situation is similar in the case of designs at a smaller scale. Many planning or urban layout projects neglect land management (roads, green areas, small architecture), focusing on cubature elements. In rare cases, the projects feature elements of land management, e.g. a fountain (Fig. 4), although even such elements, as engineering objects/structures, are built of classes typical of buildings (IfcSlab, IfcColumn, etc.).

This strengthens and accelerates the dialogue between different team members [Lorch 2012]. Benefits of a Landscape Information Model would be (a) a formalisation of knowledge in landscape design; (b) an information model to support multiple participants in landscape design; and (c) an improved information exchange between landscape design, architecture, and urban design [Zajíčková and Achten 2013]. The current hierarchy of the IFC model should be expanded by new classes for elements related to spatial planning and management, including landscape management. Landscape features are just as important as the designed cubature objects. Therefore, they should be located on the same level in the object hierarchy tree. Moreover, new classes and subclasses of infrastructural objects should be introduced at lower levels of object hierarchy (Fig. 5).

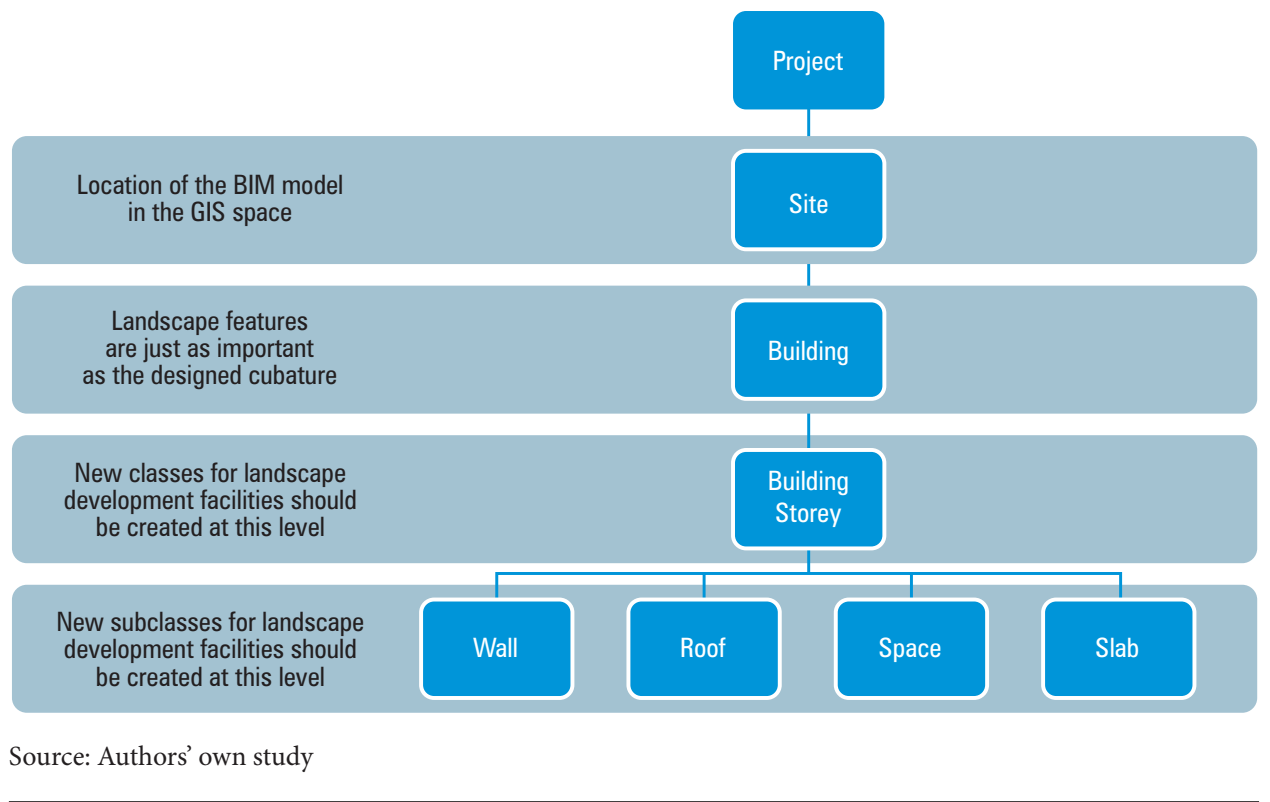

Fig. 5. Hierarchy of IFC models and proposal of new LIM elements

Figure 6 presents the most important elements directly related to the natural environment used and shaped by human activity. Both input elements, e.g. data and information generated by analyses, simulations and statistics based on the inputs should be included in the BIM model. It seems necessary to expand the BIM model by spatial integration in accordance with GIS and elements used in GIS systems (climatic, soil, hydrological, geological conditions, etc.). The LIM model should constitute an impor- 
tant part of the entire BIM model. Such a holistic approach will permit even better use of BIM technology.

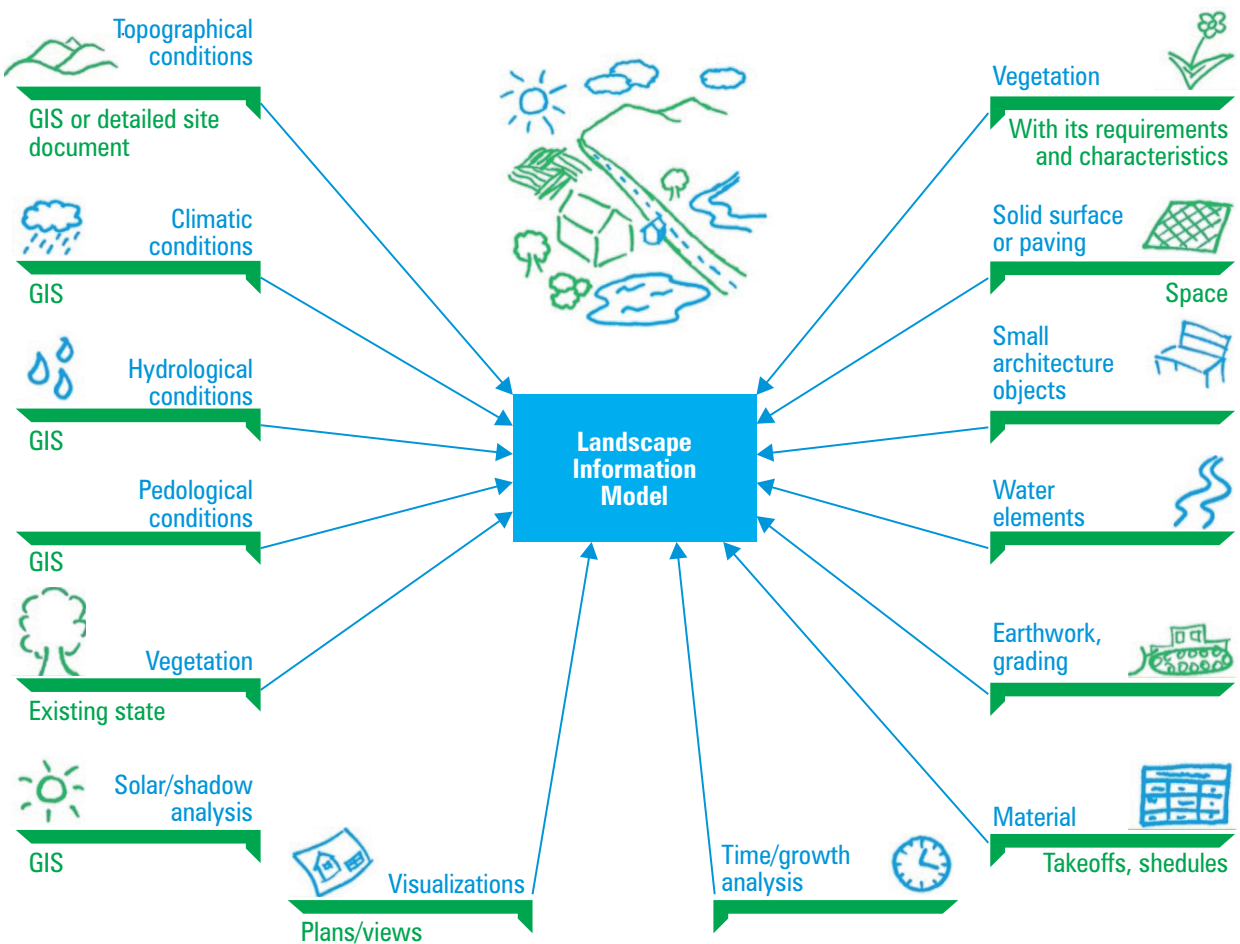

Source: Authors' own study

Fig. 6. Selected/possible elements of the LIM model

The IFC model currently primarily focuses on buildings, and covers a broad range of classes permitting the development of detailed models of buildings in the BIM technology. The current version IFC4, issued in 2016, is not suitable for modelling infrastructural objects [Vilgertshofer et al. 2017]. The buildingSMART International consortium, conducting the development of the IFC data model, appointed a number of working groups undertaking initiatives aimed at expanding the model that so far permitted saving exclusively data regarding buildings and their interiors. These working groups are open groups of specialists cooperating for the purpose of development of open solutions and IFC standards. Each group focuses on a particular domain [BuildingSMART International 2020]. Three of them are of particular importance for LIM, namely AirportRoom, InfrastructureRoom (InfraRoom), and RailRoom.

The key objective of the AirportRoom working group is a unification of standards applied in the airport industry, and supplementation of the IFC model with objects, data, and processes specifically for airports. This covers the integration of standard 
modelling processes for buildings, infrastructural objects, and airports, allowing for the management of assets, costs, risk, and efficiency of the BIM technology for the entire life cycle of airport objects [BuildingSMART 2020a]. The works of the working group are currently at the preliminary stage, and cover the development of a work plan, requirements concerning facilitated exchange of information regarding space and location between BIM and GIS systems, and preparation of the development of the Model View Definition (MVD) for GIS data. Model View Definition (MVD) is a subset of the general diagram of IFC describing the exchange of data for a particular application or process, narrowing down the thematic scope depending on the recipient's needs. It defines a subset of the IFC diagram necessary for meeting one of many exchange requirements in the AEC industry. The method applied and propagated by buildingSMART for the purpose of defining such exchange requirements is Information Delivery Manual (IDM) and norm ISO 29481 [BuildingSMART 2020b, ISO 2020].

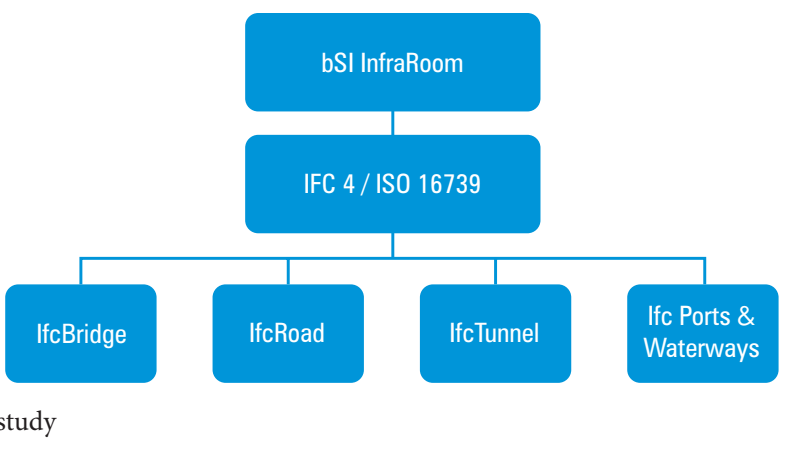

Fig. 7. List of IFC extensions for the infrastructure objects currently developed by InfraRoom (buildingSMART Switzerland 2018)

Works of the InfrastructureRoom (InfraRoom) team cover development of the IFC model for roads, bridges, tunnels, and ports (Fig. 7). The task of the team is development of common rules for obtaining integration of processes at the stage of design, building, and maintenance of infrastructure. The scope of the works involved the appointment of several sub-teams working on the expansion of the model: IFC Road, IFC Bridge, IFC Tunnel, IFC Ports \& Waterways. The key objective is to allow for data exchange based on open standards of planning, implementation, and maintenance of infrastructural works, and eventually all aspects of the construction environment [BuildingSMART International 2020]. The project is aimed to permit exchange of information and open access to data contained in asset databases, management of information on the full life cycle of infrastructural objects, and combining information related to the project, e.g. requirements and risk with asset information. The IFC Road project aims at the expansion of the IFC data model to road infrastructure by describing the semantics and geometries of roads [BuildingSMART 2019a]. The project covers linear elements of 
roads, different types of crossroads, road components, elements and equipment (road structure, road guard elements, road sign elements, road paving components), and utilities (lighting, telecommunications and power, storm-, surface- water and drainage systems, other underground facilities located below the road). The IFC Road project is also expected to cover paved surfaces of parking lots, service areas, carriageway toll plazas, and parking buildings, although these objects will not be subject to validation tests [BuildingSMART 2020]. The IFC Bridge project aims at the expansion of the IFC data model to bridge infrastructure by describing the semantics and geometries of bridges [BuildingSMART 2019b]. The scope of the project includes only the most popular types of bridges, namely Slab Bridge, Girder, Frame Bridge, RigidFrame Bridge, and Culvert. The remaining types of bridges will be covered by the IFC extension provided by the project, although they are not subject to validation tests [Moon et al. 2018]. The scope of the IFC Bridge project includes the following cases of its application: modelling of the initial state, import of main parameters of a road and railway line, technical visualisation, coordination and detection of collisions, 4D modelling of construction sequences, progress monitoring, comparison of the built object with the planned object, transfer to asset management, transfer to the GIS system for the purpose of conducting spatial analysis. Pursuant to the assumptions, each project will feature a hierarchical structure with at least three levels of hierarchy (and optional further detailed specification of elements of the bridge structure) (Fig. 8). The scope of the expansion of the IFC model proposed by the IFC Bridge team involves the development of 12 new classes of IFC objects and 37 predefined types [Borrmann et al. 2019, Hyvärinen 2019]. The IFC Tunnel project aims at the expansion of the IFC data model by data structures for tunnel buildings. It is primarily developed by the German IFC Tunnelling Project and Japanese Shield-Tunnel Project [Amann et al. 2013].

Works of the Railway Room team involve the development of the IFC model in the scope of railway infrastructure. The task of the Railway Room team is the development of common rules for obtaining integration or processes at the stage of design, building, and maintenance of railway infrastructure. The key objective of the team is cooperation with buildingSMART, owners and operators of railways, and other stakeholders, for the purpose of expanding the IFC diagram in the scope of building and maintenance of the railway domain, and development of the IFC Common Schema. The IFC Rail project aims at the expansion of the IFC data model by data structures for all lineside and trackside elements of a railway system, including track elements, power devices, signalling, and telecommunication devices. Moreover, the objective of the project is integration of the geometric model of all track and trackside elements of a railway system with all the other IFC domains: bridges, melioration systems, earth structures, geotechnics, network devices, roads, tunnels, underground devices, buildings, including stations and technical buildings [BuildingSMART International 2019]. The spatial structure of classes of objects covering the structure of buildings, roads, railway objects, bridges, and tunnel buildings is presented in Figure 8. The blue colour designates classes of objects present in the model IFC 4, and orange colour classes planned in the scope of activity of the InfraRoom (roads, bridges, and tunnels) and IFC Rail teams. 


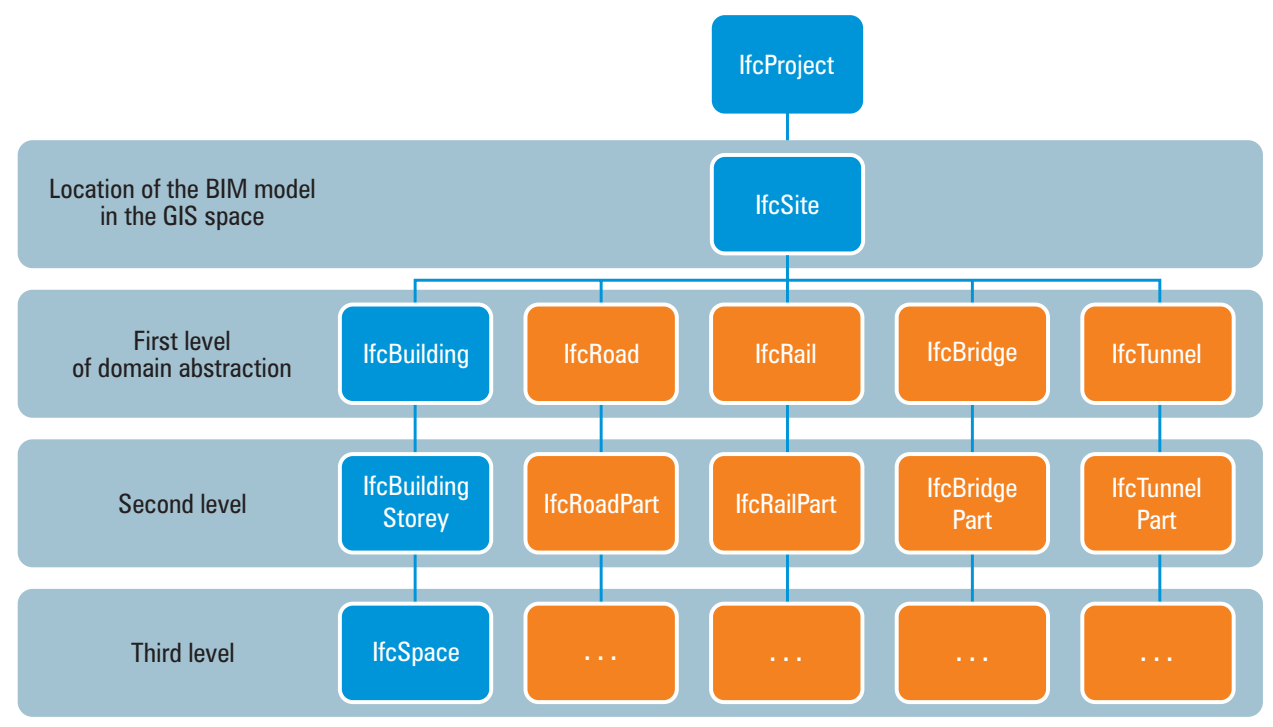

Source: Authors' own study

Fig. 8. Spatial structure of infrastructure objects proposed by buildingSMART Rooms

Next to the aforementioned projects implemented by the buildingSMART consortium, aimed at the expansion of the IFC model to permit modelling data concerning infrastructural objects, there is another project of great importance for the development of LIM. The international IFC for Site, Landscape, and Urban Planning project investigates the possibilities of further development of the IFC model by new areas: land, landscape, and urban planning, creating open methods of modelling, data flow, and data exchange for procurement, construction, and operations based on standards. An increase in interest in the BIM technology is accompanied by an increase in the number of participants of the construction process invited to the process of supplementation, integration, and exchange of data in the BIM model [BuildingSMART International 2020].

Integration of BIM and GIS is one of the ways to obtain a homogenous data set regarding cities with consideration of topographic data and data concerning building interiors. GIS and BIM show certain common features, particularly in reference to the mechanisms of verification of data errors (collision analysis and topology analysis), possibilities of development of 4D simulations, basing both systems on data processing mechanisms and susceptibility of the systems to expansion [Zhu et al. 2018]. Therefore, the GIS and BIM spaces show common features. Most importantly, they both operate on spatial data, are used for recording space information, and permit analysis and spatial visualisation. Both worlds, however, show many differences. The data model applied in BIM systems is the IFC parametric model, whereas the data model usually applied in GIS systems for describing spatial data regarding cities is the CityGML 
model, constituting a semantic model. BIM applies local coordinate systems, and GIS usually applies the global coordinate system. Data presentation in BIM systems is implemented by means of architectonic and construction norms, whereas GIS systems use rules of cartographic presentation. Differences also occur at the technical level. Data in BIM systems are stored in their own native data file formats, and GIS applies spatial databases. Network services commonly used in GIS systems are not used by BIM applications. Methods of integration of BIM and GIS are analysed and proposed in articles on the subject can be divided into five types [Fosu et al. 2015], with two main categories: data-level integration and application-level integration. Methods of BIM and GIS integration at the data level include those based on the conversion of BIM data to GIS, reverse conversion, i.e. GIS data to BIM, and development of a unified data model. Methods of BIM and GIS integration at the application level include the integration of BIM and GIS at the level of an application server and integration at the level of a client application. Multiple papers regarding BIM and GIS integration and the number of integration methods described by researchers confirm high popularity of the issue and point to the related market expectations. This study stands in a certain opposition to works conducted by the ISO Technical Committee ISO/TC 211 (Geographic information/Geomatics), involved in the development of norm ISO 19166 "Geographic information - BIM to GIS conceptual mapping (B2GM)" [ISO/TC $2112020]$. The primary assumption of the committee is as follows: Complete data integration between heterogeneous models is impossible. They have a structure developed for each purpose. However, the process of selecting and connecting the necessary data from the use case perspective can be explained [Tae Wook Kang 2020].

\section{Results}

Different types of raw data are needed at each stage of the LIM model development. They can come from both BIM and GIS systems. Spatial management objects used by LIM model are presented in the table below (Table 1). It presents sources of data in the existing GIS and BIM models, and in the planned classes of "new" BIM. The table was divided into four basic stages of work on the LIM model.

At the first stage, designers usually use reference data from GIS spatial databases in order to locate the designed object in space. It often involves the application of largescale base maps obtained from surveyors. Already during the inventory of the existing objects of land management, designers can anticipate classes of the BIM model to include such objects. At the second stage, designers conduct analyses related to the effect of the existing and designed elements of the BIM model. The concept of sustainable development assumes consideration of the hydrological, soil, topographic, or climatic (or microclimatic) conditions occurring in a given area in the context of future management. Designers conducting the analysis can again consider classes that should include a given land management element. At the third, most important stage, designers developing the model explicitly specify, usually by means of a dedicated tool in the application, the class of objects to include the element. It is of utmost importance 


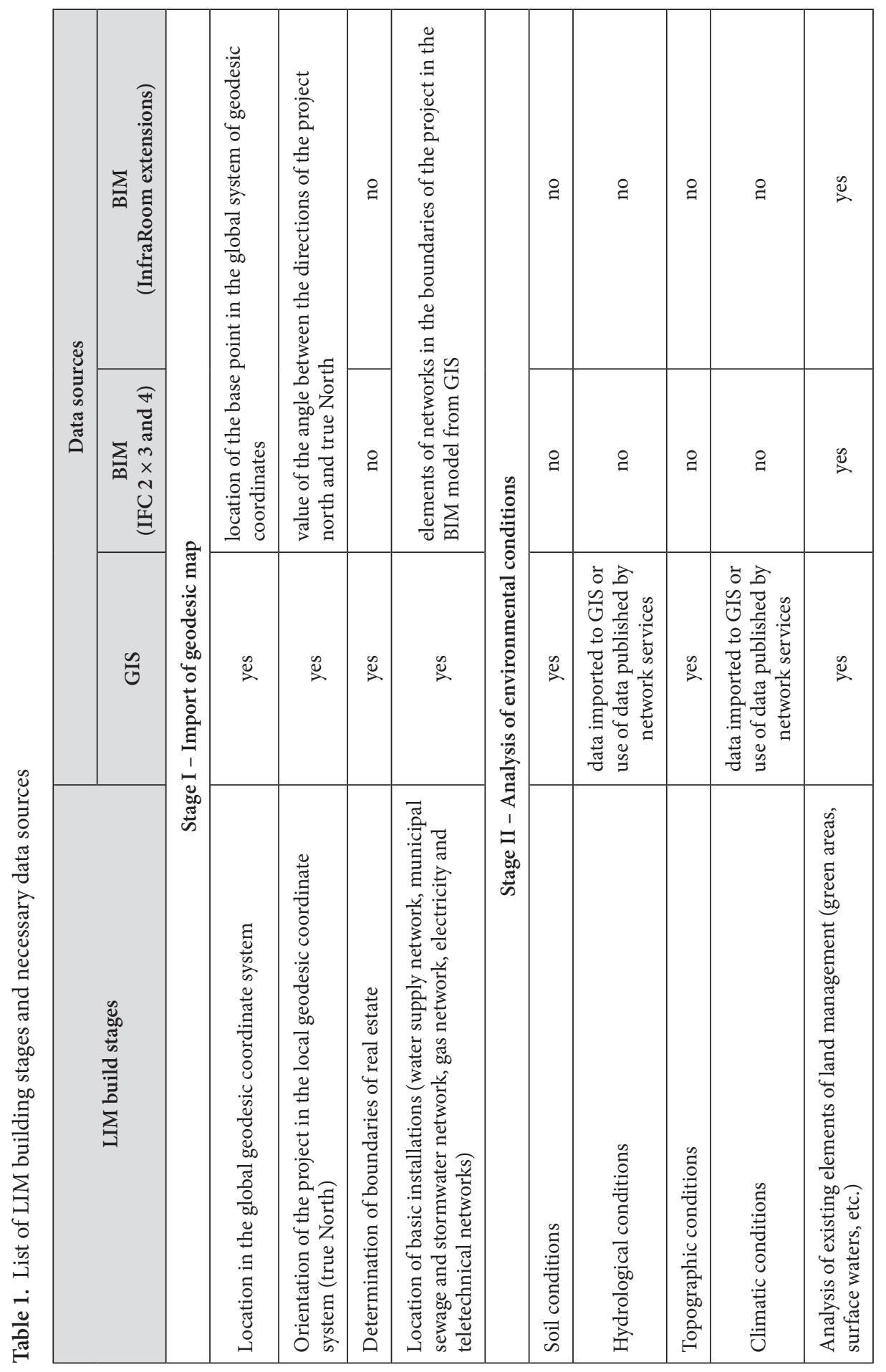




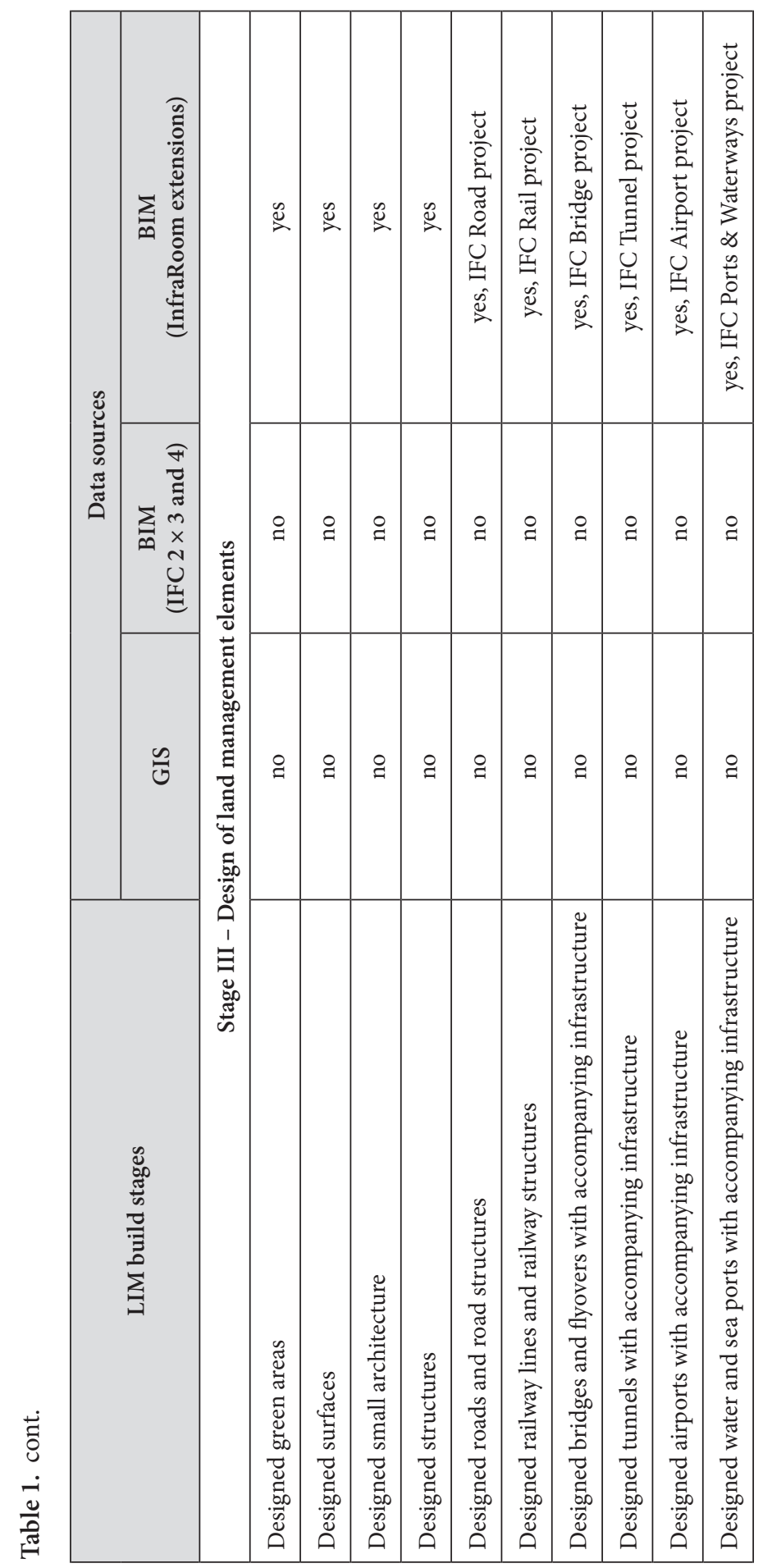




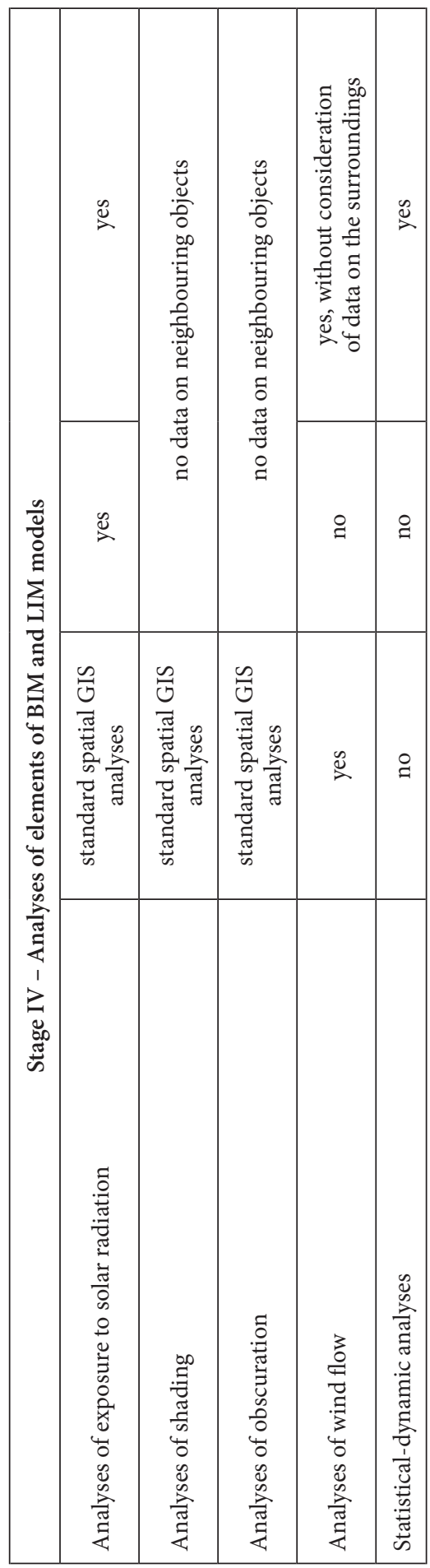


for later export of the model to the IFC format that provides for the interoperational character of work with the model. The table shows that the majority of designed land management objects will have a dedicated class in the "new" BIM (IFC4.3). The works are underway and are exceptionally desired in the AEC environment. At the fourth stage, involving analyses related to previously designed elements of land management, the importance of proper ascribing of classes stands out. In the case of chaos in this aspect, the exchange of models can be problematic, and the work itself useless. Therefore, a possibly extensive classification of objects of land management and development should be introduced as fast as possible.

\section{Summary and conclusions}

Works regarding the expansion of the IFC model by the possibility of modelling infrastructural objects have a considerable effect on the way of obtaining data for GIS systems and on LIM development. Data regarding infrastructural objects in GIS systems have been so far obtained from direct geodetic measurements. Now, a possibility appears to obtain models of these objects from BIM systems. It is of great importance for GIS systems because data regarding infrastructural objects can be obtained for GIS already at the stage of designing these objects. On the other hand, works towards BIM and GIS integration, including the developed norm ISO 19166, aim at providing two-directional data exchange between the systems. At the same time, data from GIS and BIM systems can be used by the LIM technology in the landscape modelling process. Currently created models of infrastructure objects due to the limited number of IFC classes are created using inappropriate IFC classes. Work on the development of the IFC model will lead to a situation where data on infrastructure objects used in LIM can come both from direct geodetic measurements of existing objects stored in GIS systems, as well as from BIM models created at the design stage.

\section{References}

Abdirad H., Ken-Yu L. 2015. Advancing in Object-Based Landscape Information Modeling: Challenges and Future Needs. Computing in Civil Engineering. Proceedings, 548-55. https://doi.org/10.1061/9780784479247.068.

Ahmad M., Aliyu A.A. 2012. The Need for Landscape Information Modelling (LIM) in Landscape Architecture. http://citeseerx.ist.psu.edu/viewdoc/download?doi=10.1.1.470.9995\&re $\mathrm{p}=$ rep $1 \&$ type $=$ pdf.

Amann J., Borrmann A., Hegemann F., Jubierre J.R., Flurl M., Koch Ch., König M. 2013. A Refined Product Model for Shield Tunnels Based on a Generalized Approach for Alignment Representation.

Azhar S., Khalfan M., Maqsood T. 2012. Building Information Modelling (BIM): Now and Beyond. Construction Economics and Building, 12(4), 15-28. https://doi.org/10.5130/ AJCEB.v12i4.3032.

Borrmann A., Muhic S., Hyvärinen J., Chipman T., Jaud S., Castaing Ch., Dumoulin C., Liebich Th., Mol L. 2019. The IFC-Bridge Project - Extending the IFC Standard to En- 
able High-Quality Exchange of Bridge Information Models. Computing in Construction, 1, 377-386. University College Dublin. https://doi.org/10.35490/EC3.2019.193.

BuildingSMART. 2019a. Conceptual Model Report. BuildingSMART.

BuildingSMART. 2019b. IFC Bridge Fast Track Project. Report WP2: Conceptual Model. BuildingSMART.

BuildingSMART. 2019. IFC Rail Project. Context \& Approach. BuildingSMART.

BuildingSMART. 2020a. BuildingSMART Airport Room. BuildingSMART. 2020. https://www. buildingsmart.org/standards/rooms/airport/.

BuildingSMART. 2020b. BuildingSMART Model View Definitions. BuildingSMART. 2020. https://www.buildingsmart.org/standards/bsi-standards/model-view-definitions-mvd/.

BuildingSMART. 2020. IFC Site Landscape and Urban Planning. BuildingSMART International. 2020. https://www.buildingsmart.org/standards/calls-for-participation/ifc-site-landscapeurban-planning/.

BuildingSMART. 2020. Industry Foundation Classes (IFC) - An Introduction. BuildingSMART. 2020. https://technical.buildingsmart.org/standards/ifc.

BuildingSMART. 2020. InfraRoom. IFC Road Project. Conceptual Model Report. Annex I - Example Instance Diagrams. BuildingSMART.

BuildingSMART. 2020. Infrastructure Room. BuildingSMART International. 2020. https:// www.buildingsmart.org/standards/rooms/infrastructure/.

BuildingSMART. 2020. Rooms - BuildingSMART International. https://www.buildingsmart. org/standards/rooms/.

BuildingSMART Switzerland. 2018. Bauen Digital Schweiz Home of BuildingSMART Chapter Switzerland. https://bauen-digital.ch/assets/Downloads/de/1803-buildingSMART-Switzerland-Mirror-Event2.pdf.

Fosu R., Suprabhas K., Rathore Z., Cory C. 2015. Integration of Building Information Modeling (BIM) and Geographic Information Systems (GIS) - a Literature Review and Future Needs.

Hyvärinen J. 2019. IFC Bridge Conceptual Model. BuildingSMART.

Isaac S., Curreli M., Stoliar Y. 2017. Work Packaging with BIM. Automation in Construction 83 (November): 121-133. https://doi.org/10.1016/j.autcon.2017.08.030.

ISO. 2020. ISO 29481-1:2016 Building Information Models - Information Delivery Manual Part 1: Methodology and Format. https://www.iso.org/cms/render/live/en/sites/isoorg/contents/data/standard/06/05/60553.html.

ISO/TC 211. 2020. ISO/CD TS 19166. ISO Technical Committee ISO/TC 211 Geographic information/Geomatics.https://www.iso.org/cms/render/live/en/sites/isoorg/contents/data/ standard/07/88/78899.html.

Kasznia D., Magiera J., Wierzchowiecki P. 2018. BIM w praktyce. Księgarnia Internetowa PWN.

Lorch R. 2012. BIM and the Public Interest. Building Research \& Information, 40(6), 643-644. https://doi.org/10.1080/09613218.2012.743860.

Moon H., Anderson K., Borrmann A., Hyvärinen J., Jensen J., Johansson J., Markič Š. et al. 2018. WP1 Requirementanalysis Report, IFC Bridge Project. BuildingSMART. https:// standards.buildingsmart.org/documents/IR-Road-WP2_RequirementAnalysisReport.pdf.

Tae Wook Kang. 2020. ISO 19166 BIM to GIS Conceptual Mapping China (WUHAN) Meeting. Engineering. https://www.slideshare.net/laputa999/iso-19166-bim-to-gis-conceptualmapping-china-wuhan-meeting.

Vilgertshofer S., Amann J., Willenborg B., Borrmann A., Kolbe T.H. 2017. Linking BIM and GIS Models in Infrastructure by Example of IFC and CityGML. Computing in Civil Engineering 2017, Proceedings, 133-140. https://doi.org/10.1061/9780784480823.017. 
Wyszomirski M., Borkowski A.Sz. 2019. Analiza możliwości zastosowania modelu IFC do opisania obiektów infrastrukturalnych na wybranych przykładach. Roczniki Geomatyki Annals of Geomatics 17, 1(84), 87-99.

Zajíčková V., Achten H. 2013. Landscape Information Model: Plants as the Components for Information Modelling. ECAADe 31 - Computation and Performance, 2.

Zhu J., Wright G., Wang J., Wang X. 2018. A Critical Review of the Integration of Geographic Information System and Building Information Modelling at the Data Level. ISPRS International Journal of Geo-Information, 7(2), 66. https://doi.org/10.3390/ijgi7020066.

Dr inż. Andrzej Szymon Borkowski

Department of Spatial Planning and Environmental Sciences

Faculty of Geodesy and Cartography

Warsaw University of Technology

pl. Politechniki 1, 00-661 Warszawa

e-mail: andrzej.borkowski@pw.edu.pl

ORCID: 0000-0002-7013-670X

Dr inż. Michał Wyszomirski

Department of Cartography

Faculty of Geodesy and Cartography

Warsaw University of Technology

pl. Politechniki 1, 00-661 Warszawa

e-mail: michal.wyszomirski@pw.edu.pl

ORCID: 0000-0002-5407-0536 